Article

\title{
What You Extract Is What You Get: Different Methods of Protein Extraction from Hemp Seeds
}

\author{
Annalisa Givonetti ${ }^{\dagger}$, Chiara Cattaneo $*,+(\mathbb{D}$ and Maria Cavaletto \\ Dipartimento di Scienze e Innovazione Tecnologica-DiSIT, Università del Piemonte Orientale, 13100 Vercelli, Italy; \\ annalisa.givonetti@uniupo.it (A.G.); maria.cavaletto@uniupo.it (M.C.) \\ * Correspondence: chiara.cattaneo@uniupo.it \\ † These authors contributed equally to the work.
}

Citation: Givonetti, A.; Cattaneo, C.; Cavaletto, M. What You Extract Is What You Get: Different Methods of Protein Extraction from Hemp Seeds. Separations 2021, 8, 231. https:// doi.org/10.3390/separations8120231

Academic Editor: Ernesto Reverchon

Received: 25 October 2021

Accepted: 30 November 2021

Published: 2 December 2021

Publisher's Note: MDPI stays neutral with regard to jurisdictional claims in published maps and institutional affiliations.

Copyright: (c) 2021 by the authors. Licensee MDPI, Basel, Switzerland. This article is an open access article distributed under the terms and conditions of the Creative Commons Attribution (CC BY) license (https:// creativecommons.org/licenses/by/ $4.0 /)$.

\begin{abstract}
Cannabis sativa L. seeds are rich in essential polyunsaturated fatty acids and highly digestible proteins, with a good nutritional value. Proteomics studies on hempseed reported so far have mainly been conducted on processed seeds and, to our knowledge, no optimization of protein extraction from hemp seeds has been performed. This study investigates the SDS-PAGE profile of hempseed proteins comparing different methods of extraction, (Osborne sequential extraction, TCA/acetone, MTBE/methanol, direct protein solubilization of defatted hempseed flour), two conditions to keep low temperature during seed grinding (liquid nitrogen or ice) and two solubilization buffers (urea-based or Laemmli buffer). Among the tested conditions, the combination of liquid nitrogen + TCA/acetone + Laemmli buffer was not compatible with SDS-PAGE of proteins. On the other hand, urea-based buffer achieved more reproducible results if combined with all the other conditions. TCA/acetone, MTBE/methanol, and direct protein solubilization of defatted hempseed flour demonstrated a good overview of protein content, but less abundant proteins were poorly represented. The Osborne sequential separation was helpful in diluting abundant proteins thus enhancing the method sensitivity.
\end{abstract}

Keywords: protein extraction; hempseed; seed storage proteins; SDS-PAGE

\section{Introduction}

Cannabis sativa L. is an anemophilous annual plant, one of the oldest cultivable plants in history, and its use is mainly due to the great versatility of this plant. It has been, and still is, used for the production of paper, textile fibres, paints, building products, and also for cosmetics and medicines due to the presence of bioactive compounds. Secondary metabolites, such as phytocannabinoids, as well as proteins and peptides could act as natural antioxidants and can be used in the preparation of food supplements [1-4]. Despite the numerous uses of this plant, its cultivation was banned in the first half of the twentyfirst century, due to its widespread use as a recreational drug. Only recently, the cultivation of Cannabis sativa with a low THC content has been approved, therefore increasing the diffusion of hemp varieties suitable for the production of fibre and food [5]. If in the recent past hemp seeds were used as animal feed and considered a waste product, recently their properties have been recognized for human nutrition, although their use as a food date back to more than 3000 years ago. Hempseed is considered nutritionally complete, containing 25-35\% lipids, 20-25\% proteins, 20-30\% carbohydrates, mostly represented by fibre, and a valuable source of vitamins and minerals [6]. Hempseed oil is rich in polyunsaturated fatty acids (PUFA), especially linoleic acid (omega-6) and alpha-linolenic acid (omega-3), which are essential for mammals and must be introduced with the diet [4].

The most abundant proteins in seeds are the storage proteins that provide amino acids during the germination of the seed [7]. Based on their solubility properties, seeds storage proteins can be classified into four different classes: albumins include water-soluble proteins; then there is the class of globulins which are salt-soluble proteins; prolamin class 
groups hydro-alcoholic soluble proteins; and finally, glutelins, which are soluble in alkali or acid solution [8]. The globulin family is divided into two groups based on sedimentation coefficients: 7S, called vicilins, and 11S, called legumins. The main 11S globulin present in hempseed is edestin in its 3 isoforms: edestin 1, edestin 2 and edestin 3, which are composed of subunits of $50 \mathrm{kDa}$, which are post translationally cleaved to obtain acid (30 kDa) and basic (20-22 kDa) chains, linked by a disulphide bond [9]. Globulins account for $80 \%$ of proteins present in hemp seeds, followed by albumins with 13\% [10]. Despite being low in lysine, the proteins present in these seeds are easily digestible and rich in many essential amino acids, and have a low amount of anti-nutritional factors, making them suitable for infant and pre-school children nutrition [11,12]. Protein extraction is one of the most critical steps in sample preparation and gel-based proteomic techniques are strongly influenced by the conditions used during this step, with changes in both quantity and quality of the final protein profile and related information regarding protein composition and association. Another critical step of sample preparation is low temperature maintenance to prevent protein degradation by proteases. The use of liquid nitrogen is often the first choice, since it also facilitates the disruption of plant samples while keeping them frozen. However, liquid nitrogen must be handled with care, as it is expensive and not always available in a laboratory, so a low-cost alternative is implemented by sample refrigeration on ice. This latter option does not reach temperatures as low as with liquid nitrogen and a check on the quality of protein extracts is necessary when this condition is applied for the first time to the sample. A large amount of literature on hemp proteins refers to processed hemp seeds, such as hemp protein meal obtained after oil removal, hemp protein isolate resulting from isoelectric protein precipitation, or hemp protein hydrolysates, but few proteomics studies consider hemp seeds in their natural conformation [13,14]. In this study, we aim at filling this gap by comparing different protein extraction methods from hemp seeds in attempt to find which conditions are best-suited to their SDS-PAGE analysis and show higher sustainability.

\section{Materials and Methods}

\subsection{Experimental Design}

We tested two conditions to keep low temperatures during seed grinding (liquid nitrogen or ice). The powders were fractionated following the Osborne sequential extraction or directly extracted with three methods to obtain "total" proteins (TCA/acetone, MTBE:MeOH, direct protein solubilization of defatted hempseed flour) and solubilized with two buffers (2D and Laemmli buffer) to optimize a method that is best-suited to the proteomic analysis of hempseed (Figure 1). Three independent sample extractions were performed to test each condition.

\subsection{Protein Extraction}

Hemp seeds of the variety Finola were kindly provided by ArsUniVCO, an association for the development of culture for university studies and research in the Verbano Cusio Ossola area (Italy). Hemp seed flour was obtained by grinding five grams of frozen seeds with a mortar and pestle. Two conditions for sample maintenance at cold temperatures were tested: seeds grinding in liquid nitrogen or keeping the mortar on ice. Fifty milligrams of powder were aliquoted in $2 \mathrm{~mL}$ centrifuge tubes.

Sequential fractions were extracted as indicated in [15] with some modifications. Briefly, hempseed powder was mixed with $1 \mathrm{~mL}$ of hexane to delipidate the samples. The tubes were incubated overnight at room temperature keeping the samples stirred at $250 \mathrm{rpm}$ on an orbital shaker (Multi-functional Orbital Shaker PSU-20i, bioSan, Riga, Latvia). The supernatant was removed, and the pellets were dried (Concentrator plus, Eppendorf). The albumin fraction was extracted by adding $0.5 \mathrm{~mL}$ of ultrapure water to the pellet; this step was repeated twice. The globulin fraction was obtained extracting the pellet with $0.5 \mathrm{~mL}$ of $5 \%(w / v) \mathrm{NaCl}$ solution. The prolamin fraction was extracted with $0.5 \mathrm{~mL}$ of $60 \%(v / v)$ ethanol and $2 \%$ dithiothreitol (DTT). After this step, the pellets were 
dried and the glutelin fraction was extracted with a $0.1 \mathrm{M} \mathrm{NaOH}$ solution ( $\mathrm{pH}$ 11-11.5). Each extraction step started by vortex mixing for $5 \mathrm{~min}$ and then shaking for $55 \mathrm{~min}$ at $4{ }^{\circ} \mathrm{C}$ (albumins and globulins) or at room temperature (prolamins and glutelins). The protein extracts were obtained after a centrifuge step $(12,000 \times g, 10 \mathrm{~min})$. The supernatant containing the different protein fractions were stored at $-20{ }^{\circ} \mathrm{C}$ until analysis. After each extraction step, the pellets were washed twice with the previous extraction solution, vortexed $5 \mathrm{~min}$ and centrifuged at $12,000 \times \mathrm{g}$ for $10 \mathrm{~min}$.

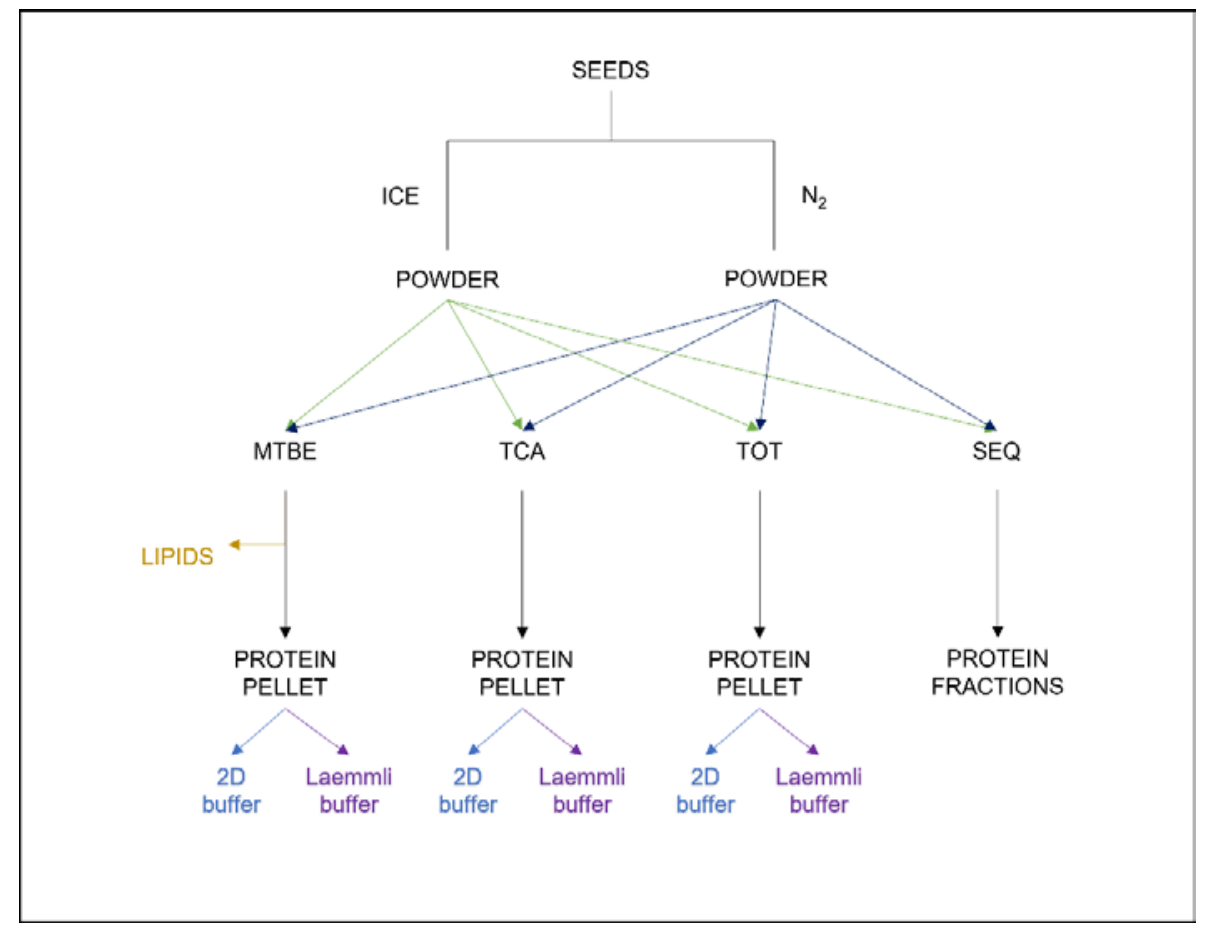

Figure 1. Workflow of experiments. ICE: powder produced by holding the mortar on ice $\left(4^{\circ} \mathrm{C}\right), \mathrm{N}_{2}$ : powder produced in the presence of liquid nitrogen. MTBE: total protein extraction after delipidation with MTBE: MeOH; TCA: total protein extraction after precipitation in TCA/acetone; TOT: total protein extraction after delipidation with hexane; SEQ: sequential protein extraction after delipidation with hexane.

TCA/Acetone protein extracts were obtained as indicated in [16]. The hempseed powder was mixed with $1 \mathrm{~mL}$ of $10 \%$ TCA in cold acetone $\left(-20^{\circ} \mathrm{C}\right), 20 \mathrm{mM}$ DTT and $1 \%$ protease inhibitors cocktail (P9599, Sigma Aldrich). The homogenate was then incubated overnight at $-20{ }^{\circ} \mathrm{C}$ to allow protein precipitation. The samples were centrifuged $\left(18,000 \times g, 1 \mathrm{~h}, 4^{\circ} \mathrm{C}\right)$ and the pellet was washed three times with cold acetone and finally dried. The samples were stored at $-20^{\circ} \mathrm{C}$ until analysis.

Protein extracts were obtained after methyl tert-butyl ether (MTBE) lipid extraction as indicated in [17]. Briefly, the powder was mixed with $1 \mathrm{~mL}$ of MTBE and methanol (MTBE:MeOH 3:1, vol/vol) refrigerated solution. The samples were vortexed for $1 \mathrm{~min}$ and then shaken $(100 \mathrm{rpm})$ for $45 \mathrm{~min}$ at room temperature. The samples were sonicated for $15 \mathrm{~min}$ in an ultrasonic bath, then $0.65 \mathrm{~mL}$ of water and methanol (3:1, vol/vol) solution were added to each tube, followed by vortexing for $1 \mathrm{~min}$ and centrifuging $(20,000 \times g$, $5^{\prime}, 4{ }^{\circ} \mathrm{C}$ ). We transferred $0.5 \mathrm{~mL}$ of the superficial phase containing lipids into new tubes, removed the rest of the lipid phase, and dried the remaining phase. The pellets were stored at $-20^{\circ} \mathrm{C}$ until analysis.

Total proteins were extracted after hemp seed powder delipidation with $1 \mathrm{~mL}$ of hexane. The sample: hexane mixtures were incubated overnight at room temperature under stirring at $250 \mathrm{rpm}$ on an orbital shaker. After hexane removal, the pellet was dried and stored at $-20^{\circ} \mathrm{C}$ until analysis. 


\subsection{Solubilization}

Protein pellets were solubilized using two different buffers: the first one was a urea containing buffer, often used for 2-D electrophoresis ( $7 \mathrm{M}$ urea, $2 \mathrm{M}$ thiourea, $4 \% w / v$ CHAPS, 100 mM DTT, IPG-buffer ( $\mathrm{pH} 3-10)$ ) which we named the "2D buffer". The second one was a Reducing Laemmli buffer ( $2 \% w / v$ SDS, $10 \%$ glycerol, 5\% 2-mercaptoethanol, $62 \mathrm{mM}$ Tris- $\mathrm{HCl} \mathrm{pH}$ 6.8), named as "LB1X-R". Irrespective of the buffer used, protein solubilization took place at room temperature for $1 \mathrm{~h}$, shaking the samples at $100 \mathrm{rpm}$ on an orbital shaker. The samples were centrifuged $\left(18,000 \times g, 10^{\prime}, 4^{\circ} \mathrm{C}\right)$ and the supernatant was transferred to new tubes.

The protein content of samples resulting from sequential extraction and 2D buffer solubilization was estimated using the Bradford assay [18] with bovine serum albumin (BSA) as the protein standard.

\subsection{Protein Analysis}

Hempseed proteins resulting from different extraction methods were analysed in triplicate by sodium dodecyl sulphate-polyacrylamide gel electrophoresis (SDS-PAGE): $10 \mu \mathrm{g}$ of protein extracts solubilized in 2D buffer were mixed with Laemmli buffer $(2 \% w / v$ SDS, $10 \%$ glycerol, $5 \%$ 2-mercaptoethanol, $62 \mathrm{mM}$ Tris- $\mathrm{HCl} \mathrm{pH} \mathrm{6.8)} \mathrm{and} 0.6 \mu \mathrm{L}$ (the same volume loaded for 2D buffer extracts) of protein extracts solubilized in LB1X-R were loaded onto $10 \times 8 \mathrm{~cm}$ vertical $12 \%$ polyacrylamide gels. Protein standards (Precision Plus Protein Dual Color Standards, Biorad) were loaded in order to estimate the apparent molecular weight of proteins.

Due to the low protein content of the prolamin fraction, we dried $50 \mu \mathrm{L}$ of this fraction in speedvac and solubilized the pellet in $5 \mu \mathrm{L}$ of LB1X-R. The samples, together with $3 \mu \mathrm{L}$ of protein standards (Precision Plus Protein Dual Xtra Standards, Biorad) were loaded onto $10 \times 8 \mathrm{~cm}$ vertical a $15 \%$ polyacrylamide gel.

SDS-PAGE was performed at $15 \mathrm{~mA}$ for $30 \mathrm{~min}$ and $30 \mathrm{~mA}$ with a Mini Protean System (BioRad). The running buffer was $25 \mathrm{mM}$ Tris- $\mathrm{HCl}, 200 \mathrm{mM}$ glycine, $0.1 \% w / v$ SDS. Gel staining was performed with Colloidal Coomassie brilliant blue G250 and the gel image was acquired by a GS-900 densitometer and image analysis of protein bands was performed by using the software ImageLab (BioRad). Results are presented as mean \pm SD of the mean $(n=3)$. Statistical analysis was performed with RStudio (version 1.3.1093) using one-way ANOVA, followed by Tukey post hoc test, Bonferroni adjustment. $p$-value $<0.05$ was considered significant.

\section{Results and Discussion}

The protein profile of samples obtained with TCA/acetone (TCA), MTBE:methanol (MTBE) and direct protein solubilization of defatted flour (TOT) methods are shown in Figure 2.

Regarding the two cooling methods (ICE vs. $\mathrm{N}_{2}$ ), no signs of protein degradation were observed, which could be revealed by an increase in the number of low MW bands. However, ICE extracts show minor bands that are less evident in $\mathrm{N}_{2}$ extracts. Besides, the ICE method was more efficient than $\mathrm{N}_{2}$ when combined with TCA/acetone precipitation and LB1X-R solubilization, where the protein profile is almost absent. In fact, after solubilization, these samples had a $\mathrm{pH}$ of 3 and needed to be neutralized with $\mathrm{NaOH}$, but this procedure did not provide an efficient protein separation.

Thus, the production of hempseed powder for the purpose of extracting proteins seems to work best on ice.

Considering the same method of powder production and protein extraction, the 2D buffer extracts showed higher molecular weight bands (over $75 \mathrm{kDa}$ ) compared to the LB1X-R buffer ones. 


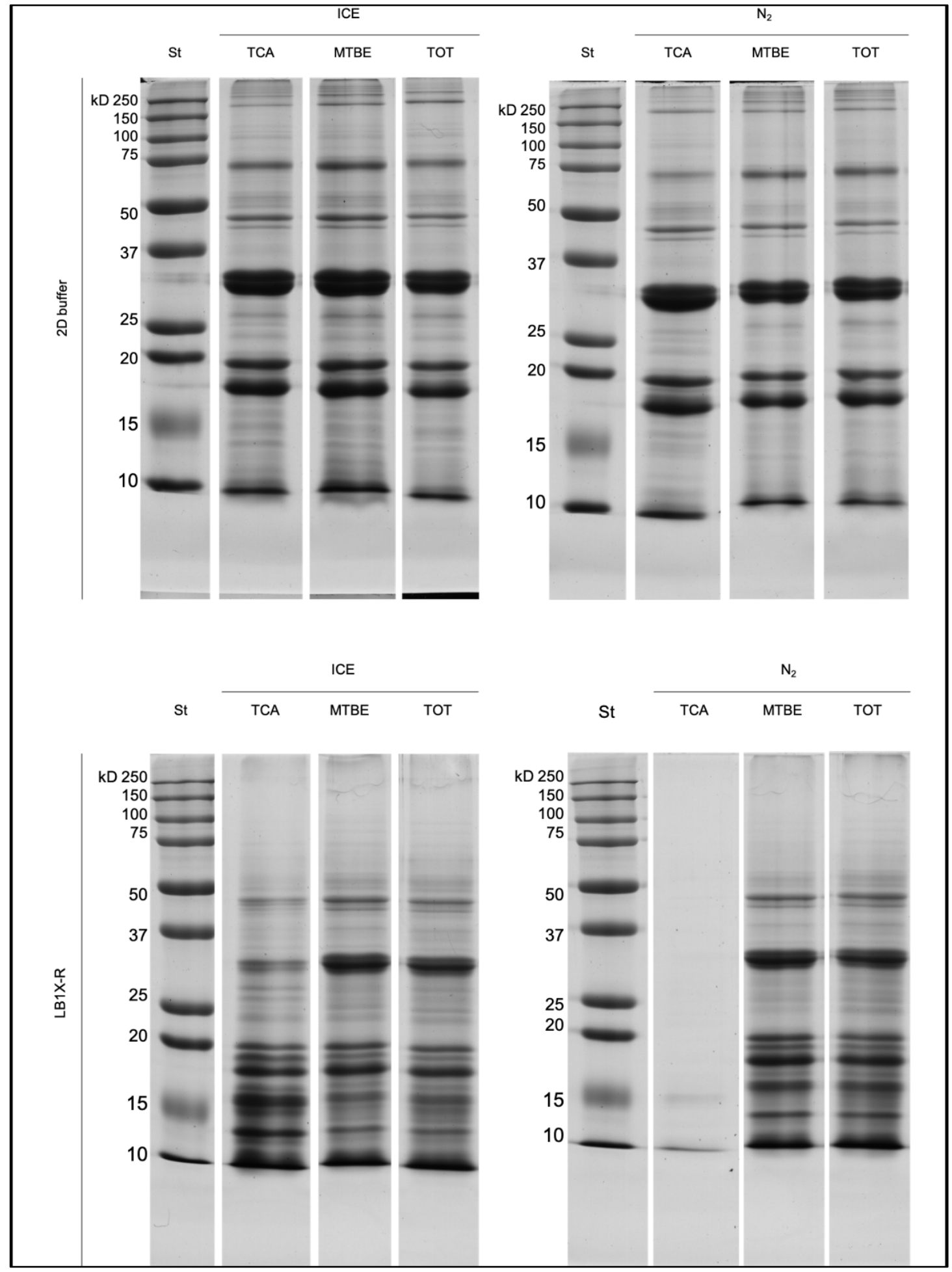

Figure 2. SDS PAGE of ICE + 2D buffer extracts and $\mathrm{N}_{2}+2 \mathrm{D}$ buffer extracts, ICE + LB1X-R buffer extracts and $\mathrm{N}_{2}+$ LB1X-R buffer extracts. Three different methods are compared: TCA/Acetone precipitation (TCA), MTBE:MeOH delipidation (MTBE), hexane delipidation (TOT).

The molecular weight bands at about $75 \mathrm{kDa}$ of 2D buffer extracts can be ascribed to edestin 1, vicilin C72-like, heat shock $70 \mathrm{kDa}$ protein-as identified in [4]. The appearance of such bands depending on the solubilizing buffer is in accordance with the observations of Mamone [19], where the presence of edestin at $50 \mathrm{kDa}$ was observed after 2D-electrophoresis under reducing conditions. 
On the other hand, the profile of the LB1X-R extracts is similar to that obtained from hemp flour by [19], with highly intense bands at about 30 and $20 \mathrm{kDa}$, where the acid and basic subunits of the three isoforms of edestin can be identified.

To compare the performance of the methods, image analysis of the bands was conducted, and the optical density (OD) mean and standard deviation, together with statistic parameters, are reported in Supplementary Material 1. The most significant bands, presenting at least 2-fold differences in the OD values, are shown in Figure 3 and here discussed.

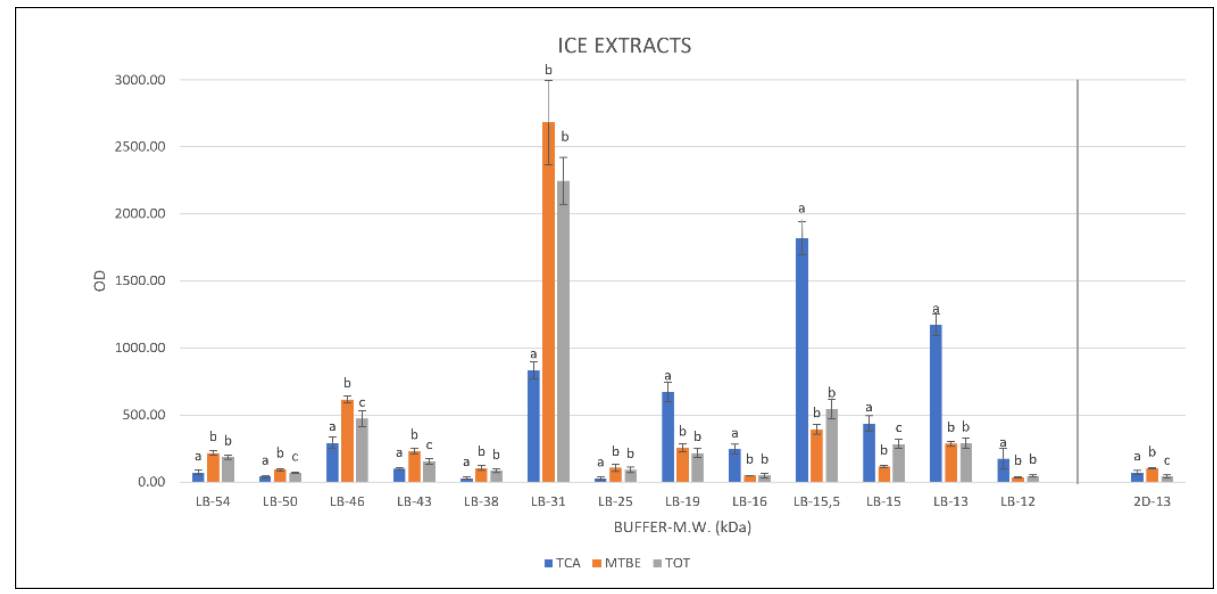

Figure 3. Histogram representing the optical density (mean \pm standard deviation), of SDS-PAGE protein bands with at least 2-fold differences among ICE extracts obtained with TCA, MTBE and TOT methods. The grey vertical bar divides LB1X-R (left side) from 2D-buffer solubilized samples (right side). Significant different values ( $p$-value $<0.05)$ are indicated by different letters.

We can observe that the TCA, MTBE and TOT profiles of 2D buffer extracts are quite similar to each other, except for the $13 \mathrm{kDa}$ band observed in ICE-2D extracts, which is less intense in TOT samples.

On the other hand, ICE-TCA-LB1X-R extracts show a decrease in band intensity over $20 \mathrm{kDa}$ and an increase under the same MW compared with the other two methods.

The result of sequential extraction is shown in Figure 4. The pattern of the albumin fraction of $\mathrm{N}_{2}$ extracts has fewer bands above $100 \mathrm{kDa}$, between 30-25 and 20-15 kDa when compared with ICE extracts.

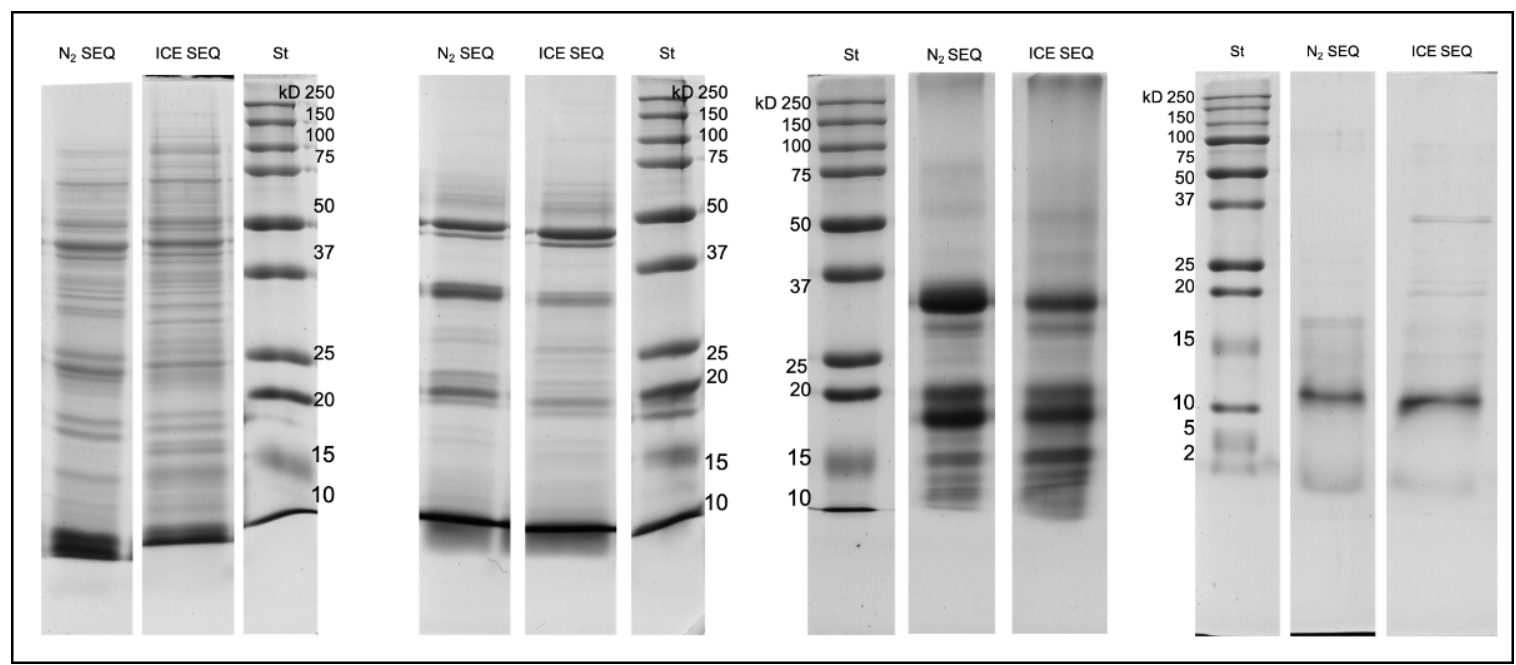

Figure 4. SDS PAGE of different protein fractions, from left to right: $\mathrm{N}_{2}$ and ICE albumins, $\mathrm{N}_{2}$ and ICE globulins, $\mathrm{N}_{2}$ and ICE glutelins. $\mathrm{N}_{2}$ and ICE prolamins. 
The protein pattern of the globulin and glutelin fractions is quite similar in both conditions. The electrophoretic profile of the prolamin fraction of the two samples differs in the distribution of bands above $10 \mathrm{kDa}$ : the $\mathrm{N}_{2}$ extracts have no bands above $18 \mathrm{kDa}$, while ICE extracts show two bands at about $37 \mathrm{kDa}$.

Three bands at about 30, 20 and $18 \mathrm{kDa}$ are evident in the glutelin fraction. In this case, the band intensity is higher in $\mathrm{N}_{2}$ than in ICE extracts. As previously mentioned, in this MW range the acid and basic chains of edestin are usually identified. As found in the literature, the solubility of globulins increases with the increase in $\mathrm{pH}$ [20]. Probably, edestin aggregates were more strongly associated after the $\mathrm{N}_{2}$ treatment and could be efficiently extracted only under alkaline conditions. It is thus evident that the sequential extraction does not uniquely separate the proteins based on their solubility but helps to fractionate the sample to make the proteins present in small quantities that otherwise would not be possible to identify from a total extract more visible. The electrophoretic profile of the prolamin fraction of the two samples differs in the distribution of bands above $10 \mathrm{kDa}$ : the $\mathrm{N}_{2}$ extracts and have no bands above $18 \mathrm{kDa}$, while ICE extracts show two bands at about $37 \mathrm{kDa}$.

\section{Conclusions}

The ICE method seems to be the one that gives the best results, being simpler and safer and preserving the sample from degradation.

Reducing the Laemmli buffer showed a greater denaturing and reducing action compared to the urea-based buffer. The presence of high MW bands only in 2D-buffer extracts could be a sign of inefficient removal of protein aggregates and needs to be taken into account when performing 2D-electrophoresis. However, 2D-buffer extracts showed minor variability in the OD of bands, giving more reproducible results among the methods tested.

The MTBE method was comparable to the others with the advantage of preserving the lipid fraction for the specific analysis. Moreover, with this method it is possible to obtain a good representation of hempseed proteins using both urea-based and Laemmli solubilization buffers.

TCA/acetone, MTBE/methanol, and direct solubilization of defatted hemp seed flour demonstrated a good overview of protein content, but the detection of less abundant proteins can be enhanced by the use of the Osborne sequential separation.

Supplementary Materials: The following are available online at https:/ / www.mdpi.com/article/ 10.3390 / separations $8120231 /$ s1.

Author Contributions: Conceptualization, A.G. and C.C.; methodology, A.G. and C.C.; writingreview and editing, A.G. and C.C.; supervision, M.C. All authors have read and agreed to the published version of the manuscript.

Funding: This research was supported by the University of Piemonte Orientale, grant: bando ateneo ricerca FAR17.

Institutional Review Board Statement: Not applicable.

Informed Consent Statement: Not applicable.

Data Availability Statement: The data can be available upon reasonable request.

Acknowledgments: We thank ArsUniVCO for the recruitment of hemp seeds and Nigel Joyce for proofreading the article.

Conflicts of Interest: The authors declare no conflict of interest. 


\section{References}

1. Bonini, S.A.; Premoli, M.; Tambaro, S.; Kumar, A.; Maccarinelli, G.; Memo, M.; Mastinu, A. Cannabis sativa: A comprehensive ethnopharmacological review of a medicinal plant with a long history. J. Ethnopharmacol. 2018, 227, 300-315. [CrossRef]

2. Pavlovic, R.; Panseri, S.; Giupponi, L.; Leoni, V.; Citti, C.; Cattaneo, C.; Cavaletto, M.; Giorgi, A. Phytochemical and Ecological Analysis of Two Varieties of Hemp (Cannabis sativa L.) Grown in a Mountain Environment of Italian Alps. Front. Plant Sci. 2019, 10, 1265. [CrossRef] [PubMed]

3. Tremlová, B.; Mikulášková, H.K.; Hajduchová, K.; Jancikova, S.; Kaczorová, D.; Ćavar Zeljković, S.; Dordevic, D. Influence of Technological Maturity on the Secondary Metabolites of Hemp Concentrate (Cannabis sativa L.). Foods 2021, 10, 1418. [CrossRef] [PubMed]

4. Cattaneo, C.; Givonetti, A.; Leoni, V.; Guerrieri, N.; Manfredi, M.; Giorgi, A.; Cavaletto, M. Biochemical aspects of seeds from Cannabis sativa L. plants grown in a mountain environment. Sci. Rep. 2021, 11, 3927. [CrossRef] [PubMed]

5. Farinon, B.; Molinari, R.; Costantini, L.; Merendino, N. The seed of industrial hemp (Cannabis sativa L.): Nutritional Quality and Potential Functionality for Human Health and Nutrition. Nutrients 2020, 12, 1935. [CrossRef] [PubMed]

6. Callaway, J.C. Hempseed as a nutritional resource: An overview. Euphytica 2004, 140, 65-72. [CrossRef]

7. Shewry, P.R.; Napier, J.A.; Tatham, A.S. Seed storage proteins: Structure and biosynthesis. Plant Cell 1995, 7, 945-956. [CrossRef] [PubMed]

8. $\quad$ Osborne, T.B. The Vegetable Proteins; Longmans: London, UK, 1924.

9. Shewry, P.R. The Protein Chemistry of Dicotyledonous Grains. In Encyclopedia of Grain Science; Walker, C., Wrigley, C., Corke, H., Eds.; Elsevier Academic Press: Amsterdam, The Netherlands, 2004; pp. 466-472.

10. Wang, X.S.; Tang, C.H.; Yang, X.Q.; Gao, W.R. Characterization, amino acid composition and in vitro digestibility of hemp (Cannabis sativa L.) proteins. Food Chem. 2008, 107, 11-18. [CrossRef]

11. Tang, C.H.; Ten, Z.; Wang, X.S.; Yang, X.Q. Physicochemical and functional properties of hemp (Cannabis sativa L.) protein isolate. J. Agric. Food Chem. 2006, 54, 8945-8950. [CrossRef] [PubMed]

12. Arbach, C.T.; Alves, I.A.; Serafini, M.R.; Stephani, R.; Perrone, Í.T.; de Carvalho da Costa, J. Recent patent applications in beverages enriched with plant proteins. NPJ Sci. Food 2021, 5, 28. [CrossRef] [PubMed]

13. Park, S.K.; Seo, J.B.; Lee, M.Y. Proteomic profiling of hempseed proteins from Cheungsam. Biochim. Biophys. Acta 2012, 1824, 374-382. [CrossRef] [PubMed]

14. Aiello, G.; Fasoli, E.; Boschin, G.; Lammi, C.; Zanoni, C.; Citterio, A.; Arnoldi, A. Proteomic characterization of hempseed (Cannabis sativa L.). J. Proteom. 2016, 147, 187-196. [CrossRef] [PubMed]

15. Dai, H.; Zhang, X.Q.; Harasymow, S.; Roumeliotis, S.; Broughton, S.; Eglinton, J.; Wu, F.; Li, C. MALDI-TOF mass spectrometry provides an efficient approach to monitoring protein modification in the malting process. Int. J. Mass Spectrom. 2014, 371, 8-16. [CrossRef]

16. Méchin, V.; Damerval, C.; Zivy, M. Total protein extraction with TCA-acetone. Methods Mol. Biol. 2007, 355, 1-8. [CrossRef] [PubMed]

17. Salem, M.; Bernach, M.; Bajdzienko, K.; Giavalisco, P. A Simple Fractionated Extraction Method for the Comprehensive Analysis of Metabolites, Lipids, and Proteins from a Single Sample. J. Vis. Exp. 2017, 124, 55802. [CrossRef] [PubMed]

18. Bradford, M. A rapid and sensitive method for the quantitation of microgram quantities of protein utilizing the principle of protein-dye binding. Anal. Biochem. 1976, 72, 248-254. [CrossRef]

19. Mamone, G.; Picariello, G.; Ramondo, A.; Nicolai, M.A.; Ferranti, P. Production, digestibility and allergenicity of hemp (Cannabis sativa L.) protein isolates. Food Res. Int. 2019, 115, 562-571. [CrossRef] [PubMed]

20. Potin, F.; Lubbers, S.; Husson, F.; Saurel, R. Hemp (Cannabis sativa L.) Protein Extraction Conditions Affect Extraction Yield and Protein Quality. J. Food Sci. 2019, 84, 3682-3690. [CrossRef] [PubMed] 